\title{
INTRODUÇÃO: A OPERACIONALIDADE DO JOGO
}

Fernanda Eugenio \& Ricardo Seiça Salgado ${ }^{1}$

AND Lab, Rio de Janeiro, Brasil / CRIA-UMinho, Braga, Portugal

A chamada para artigos deste dossiê pretende discutir o conceito de jogo na sua operacionalidade nomeadamente como o jogo serve de laboratório experimental de procedimentos, como o jogo é posto em prática e que consequências este fazer proporciona, contribuindo para uma heurística da análise sociocultural. O foco elenca então a articulação de vários "comos":

1) a forma como o jogo se faz dispositivo (ou contra-dispositivo do senso comum) para a invenção coletiva e dissensual do comum, permitindo desvincular a prática da comunidade dos mecanismos identitários da pertença e da reprodução, bem como re-situar o seu entendimento enquanto processo de vinculação sempre em aberto: nem essência nem substância, mas potência de relação que está sempre por ser efetuada a cada vez;

2) a forma como o jogo está a ser ativado, em diferentes áreas, enquanto prática exploratória - explicitando o que um corpo pode e contribuindo para a reimaginação da corporeidade e dos modos de estar no mundo;

3) a forma como o jogo pode funcionar como plano de re-performance e/ou como chave analítica para dar a ver as complexas relações éticas, estéticas e políticas implicadas na constante negociação social dos lugares de fala, das representações e das formações subjetivas;

4) a forma como o jogo é usado para a reinvenção de práticas pedagógicas e de práticas metodológicas;

5) a forma como o jogo, nas suas engrenagens e de dinâmica processual, se relaciona com a utopia ou com a vanguarda e se pode concretizar enquanto heterotopia.

1 Contato dos autores: fe.eugenio@gmail.com / ricardoseica@gmail.com. 


\section{PARA UMA DEFINIÇÃo DE JOGO}

O conceito transdisciplinar de jogo aparece ao longo das várias epistemologias e teorias resultantes que lhes estão subjacentes numa espécie de batalha que já vem da era helênica, entre Dionísio e Apolo (Spariosu 1989). Em Dionísio, a ideia de jogo aparece como algo pré-racional, seja a manifestação de um incessante devir, seja um modo de ser que opera no "como se", numa liberdade irrestrita, uma mimese-jogo em que o poder se representa a si mesmo como o jogo do devir físico livre, espontâneo e violento, num mundo aleatório de forças e conflitos arbitrários e que denotam a fantasia agonística dos deuses. Roger Caillois (1990) diria a paidia - a possibilidade completa do jogo livre improvisado, fantasioso, coberto de energia, entusiasmo, diversão e turbulência. Há vários adjetivos que dão conta deste descentramento do jogo, todos eles abordando o mesmo território de significado. Sutton-Smith (2001: 56) chama de "jogo cruel", ou "máscaras do jogo" o que Schechner (1993) chamou de "jogo obscuro" (dark play), um conceito que envolve fantasia, risco, sorte, que subverte a ordem, dissolve os enquadramentos, quebrando as suas próprias regras. É o lado subversivo do jogo, uma vez que as suas agendas estão escondidas, dissimuladas. Da antropologia, conhecemo-lo como "jogo profundo" ou "jogo absorvente” (deep play), formulado por Clifford Geertz (1993). É o território da ousadia, tomar a sorte na potência de um mundo de possibilidades, mas também a prática de uma comunidade que se reinventa, que produz cultura.

Do outro lado da ambiguidade que é o jogo, Apolo complementa de forma antitética e determina, por assim dizer, o que o senso comum deve saber incorporar. Aqui toma-se o jogo como uma interação determinada pelas regras da necessidade e do acaso, como uma liberdade racional ou limitada, uma mimese-imitação em que o poder se apresenta como Ser, Razão e ordem imutável (Spariosu 1989: 19). A esta tendência, Caillois (1990) chamou de ludus, resultante da tendência disciplinadora, em que as regras e convenções se sedimentam no jogo, controlando os comportamentos possíveis dos jogadores. O problema é que ao longo da história das várias correntes filosóficas ocidentais, como Spariosu no mesmo texto adverte, tem sido difícil produzir uma teoria que conecta os dois paradigmas. Como nos diz Robert Fagen (em SuttonSmith 2001: 2), o conceito de jogo escarnece-nos com a sua inacessibilidade. Pressentimos que há algo por detrás dele e que desconhecemos, ou esquecemos o modo como "chegar lá!"

A ambiguidade do jogo emerge, em primeiro lugar, da sua natureza. Gregory Bateson (1987) demonstrou o caráter paradoxal do jogo, na medida em que o jogo "é" e, simultaneamente, "não é" o que aparenta ser. Uma beliscadura brincalhona, por exemplo, pode não ser uma mordidela mas é, de facto, o que uma mordidela significa, a forma de indicar um negativo através de uma ação afirmativa que é claramente desigual ao que representa (ibidem: 140). Schechner (Sutton-Smith 2001: 1) acrescenta que uma beliscadura brincalhona não é apenas uma não-mordidela, é igualmente uma não-não-mordidela, sugerindo que é positiva a soma de dois negativos. Assim, para Bateson, a natureza paradoxal do jogo é que ele não é somente jogo, é igualmente uma mensagem sobre si próprio, uma metamensagem. Pertence simultaneamente ao mundo e não é deste mundo. O jogo é um tipo de comunicação, na medida em que a mensagem "isto é jogo" é percebida e, com ela, operam os comportamentos que lhe estão subjacentes. Sutton-Smith (ibidem: 23) acrescenta ainda que o jogo, para além do tipo ou modo de comunicação, é igualmente um tipo de ação, uma categoria distinta do comportamento.

Huizinga (2003) define jogo e relaciona-o com a cultura. Walter Benjamin (2002) diz-nos que o hábito entra na vida como jogo, mobilizando emoções e inspirando prazer, embora exigin- 
do repetição ou mimese renovada. Sutton-Smith (2001: 214-231), indo mais longe, numa revisão de estudos das várias disciplinas do conhecimento, define o jogo como uma "facsimilização da luta pela sobrevivência”, uma vez que há uma transferência potencial de aptidões que o jogo trabalha para a vida produzindo, assim, uma retórica-síntese: o jogo como variabilidade adaptativa. $\mathrm{O}$ jogo reforça a variabilidade do organismo para fazer face a "rigidificações da adaptação bem-sucedida", a um adormecimento dos procedimentos que possa vir a comprometer o futuro. Por isso, o jogo funciona justamente como um laboratório experimental de procedimentos, de mecanismos de produzir extensões que amplificam a capacidade de resposta de um organismo perante o desconhecido ou uma qualquer adversidade. Há um potencial adaptativo no jogo.

Apoiando-se nos três princípios que Stephen Gould atribui à variabilidade que caracteriza a evolução biológica (ibidem), em vez de precisão na adaptação, as várias metáforas do jogo são constituídas num modelo de variabilidade. Em primeiro lugar, estruturalmente, o jogo (como a evolução biológica), é caracterizado por mudanças subtis e peculiares. Há um potencial latente, uma excentricidade que acontece e que perdura. Depois, o processo subjacente a estas mudanças excêntricas do jogo são redundantes, isto é, não são imediatamente requeridas para a adaptação, não têm função imediata na vida. Reproduzem-se, antes, em estruturas similares potencialmente disponíveis para o futuro. E finalmente, a variabilidade excêntrica e a redundância múltipla são geradas de uma forma flexível, algo que pode estar na base do jogo ser motivante e estimulante, aquilo que Csikzentmihalyi $(1975 ; 2002)$ chama de experiência autotélica, ou fluxo.

As principais características da experiência ótima que é o fluxo são (ibidem): claridade nos objetivos e no feedback auferido; envolvimento intenso no fazer; uma perda de sentido do tempo; concentração profunda; mas, simultaneamente, há uma falta de autoconsciência. Há uma transcendência do sentido de self, conduzindo a uma experiência autotélica (que tem um fim em si mesmo, não necessita de objetivos ou recompensas exteriores ao próprio jogo), uma experiência intrinsecamente recompensadora. Se as aptidões forem maiores que as exigências facilmente o aborrecimento substitui o fluxo; é possível vir a despertar ansiedade se as aptidões forem inadequadas e os desafios decisivos; se houver uma falta de aptidões e de desafios, a apatia será o mais certo. A própria possibilidade da batotice fratura a crença no dispositivo que o jogo promete, quebra as regras, mas também contribui para a quebra do fluxo, não se constituindo, como tal, num comportamento alternativo.

Tanta replicação, tanto prazer, tanta flexibilidade sugere que a função do jogo seria então a de reforçar a variabilidade adaptativa do organismo (Sutton-Smith 2001). Tal facto é congruente com o papel que tem na variabilidade cultural, na produção de comportamentos alternativos em grupo. Quando no campo da arte, o jogo toma um papel preponderante na produção das vanguardas artísticas. Pelo menos no campo das artes da performance, cada linguagem ou lógica de procedimentos em experimentação é ativado por um treino específico que a veicula e que emerge em grande medida a partir de jogos ou exercícios desenvolvidos, enquanto ferramentas do fazer.

Estruturar o esforço para uma definição de jogo, tal como nos sugere Schechner (1993: 25-26), determina a modelação da sua definição, configurando: (1) a estrutura do jogo: leva-nos a encará-lo sincronicamente e a perceber as unidades de comportamento que se constituem e se encaixam num todo coerente, atos que requerem um certo tipo de relações para que o evento se constitua num ato inserido no jogo; (2) o processo do jogo: olhamos agora o jogo diacronicamente referindo-nos às várias fases do seu desenvolvimento, às estratégias empregues e aconte- 
cimentos em cada fase do jogo e como elas o vão determinando, em todas as suas consequências, até ao fim do jogo. A estrutura e o processo devem ser encarados como um par relacionado; (3) a experiência de jogar: refere-se aos sentimentos, aos temperamentos dos jogadores e dos espectadores, às suas experiências, e de como é que elas afetam o desempenho, como vão mudando e se chega à conclusão de que o jogo foi bom ou mau; (4) a função do jogo: mostra os propósitos que o jogo serve, a forma como afeta a aprendizagem, o crescimento e a criatividade individual e coletiva; (5) a ideologia do jogo: aponta para os valores políticos, sociais e individuais que um jogo enuncia, propaga, critica, e expressa (explícita ou implicitamente); (6) O enquadramento tem que ver com a determinação do contexto e dos procedimentos específicos do contexto, em ordem à interpretação (Stewart 1989). Diz respeito ao que informa os jogadores e espectadores que o jogo começa, acontece e acaba, e em como a mensagem "agora estou a jogar" é recebida e interpretada, isto é, que meta-jogo enquadra determinado jogo.

Avança-se então uma síntese das qualidades estruturais do jogo: (1) envolve voluntariedade para jogar e liberdade no jogo que se joga; (2) produz o reenquadramento das mensagens, o que implica uma sensação de deslocamento, de transformação do quotidiano; conjuntividade e, por isso, transporte do jogador para uma outra mundividência (Schechner 1985); (3) um conjunto de regras ou procedimentos para a interpretação que pode não ser consentânea com as da vida real; (4) metacomunicação (Bateson 1987), uma vez que o jogo começa por se referir a si próprio, introduzindo a possibilidade de se reinventar e reclassificar as ações, e desenvolver novos enquadramentos, mesmo que paradoxalmente; (5) reflexividade, isto é, a ação exerce-se sobre a própria prática do jogo, e sobre o sujeito que o pratica; (6) liminaridade (Turner 1992) e paradoxo, está no domínio do "como se". O jogo não é aquilo que representa e, portanto, o que representa não existe. Ao ser liminar, inverte e subverte a realidade e a estrutura social mundana, e todos os papéis que nela desempenhamos podem desconhecer a lógica das hierarquias impostas na esfera pública. Em última análise, "a sabedoria transmitida na liminaridade (...) tem valor ontológico, remodela o ser” (Turner 1974: 127), e fá-lo através de uma invisibilidade estrutural; (8) o jogo envolve expressões, isto é, objetivações, representações, sedimentações que resultam da experiência do ato de jogar.

O jogo é um estado de espírito, um modo de ver, de ser e de estar, uma atitude, um querer que se projeta para o futuro. $\mathrm{O}$ que será adaptativo no jogo podem não ser as aptidões que fazem parte dele, mas a confiança, convicção e desejo da sua própria capacidade para um futuro. É como se o oposto do jogo fosse a depressão, a vacilação, o estéril. Gadamer (1999) demonstra a realidade objetiva do estado existencial que o jogo induz ou elicia. $\mathrm{O}$ jogo é uma espécie de resgate, uma energia de pura realização, em que as reações são mais involuntárias que voluntárias; o jogo toma conta do self, é independente dos jogadores e consiste numa espécie de movimento de um lado para o outro, sem outro objetivo que não seja dentro e para o próprio jogo. Evidentemente que cada um se voluntaria para jogar. Contudo, uma vez dentro do jogo, é ele que nos joga, renovando-se em cada permanente repetição. É o jogo que determina a atitude do jogador emergindo, portanto, igualmente, uma presença ou auto(re)presentação do jogador, para além do jogador "ser jogado" (Spariosu 1989: 138).

O jogo não tem outro propósito que não o de se referir a si próprio, embora, surpreendentemente, a sua natureza torna-se central para a vida real. O jogo abre espaço de possibilidade para a experimentação, retirando-se dos hábitos, do rigor e inflexibilidade da consciência. Sutton-Smith (2001: 157-159) serve-se do estudo de Greta Fein, para referir que o "jogo a fingir" das crianças é frequentemente uma distorção absurda ou ridícula do mundo de expecta- 
tivas, é extravagante, exagerado, roça o bizarro. O que se sugere é que as fantasias das crianças não são apenas miméticas (a mimese-imitação), no sentido de replicação do mundo, elas servem para criar um outro mundo que segue o seu próprio curso, funcionando também por via da metonímia (a mimese-jogo). E essa experiência da vida própria do "jogo a fingir" excede-se a si própria, confere prazer, motiva, é uma experiência que transcende os seus limites habituais.

É por isso melhor pensar o jogo como um advérbio, como nos sugere Susan Millar (1971). Como advérbio, o jogo produz possibilidades, junta-se aos verbos, adjetivos e outros advérbios para lhes mudar a significação. Tal facto indica que talvez seja melhor definir o jogo pelo que ele faz, pela sua função, em vez de lhe dar uma definição pelo que significa (Spariosu 1989: 3). É preciso olhar o jogo como um conceito operatório. É esse o propósito do jogo, a criação de mais possibilidades para ele próprio, a expansão. Isto distingue-o da criatividade, onde se produzem objetos em que se implica sempre a objetivação e não apenas a sua existência enquanto universo de possibilidade. Se o jogo não precisa necessariamente de ser criativo, a criatividade precisa do jogo. O jogo está "entre" e "para além". Como diz Turner, "talvez [o jogo] seja o modo mais apropriado de performance" (Turner 1986: 32, parêntesis retos meus).

\section{ESTRUTURA DO DOSSIÊ}

A escolha dos artigos para este dossiê teve em conta os princípios delineados nesta introdução, jogando com a articulação de vários "comos". Faz algum tempo que o Ricardo e a Fernanda se prometiam a si próprios olhar em conjunto o Modo Operativo AND, uma prática da convivência e experimentação do comum que a Fernanda desenvolve há muitos anos. Publicamos finalmente um ensaio-conversa que consuma justamente esse desejo, sob o título $O$ AND é jogo? Ensaio-conversa à volta da operacionalidade do jogo no Modo Operativo AND. O tema adensa-se com o artigo seguinte de Ana Dinger, agora ela a olhar para o AND: em $A N D \ldots$ What's in a name?... AND... What's in a game?, explora o que se aglutina no conectivo E evocado nesta prática, desdobrando outras dimensões em que o jogo atua no âmbito desta pesquisa, nomeadamente o plano dos jogos de palavras que permitem ir constituindo um vocabulário comprometido com a performatividade dos conceitos, tornados ferramentas.

Abrindo o jogo AND, embora não saindo totalmente dele, Sílvia Pinto Coelho continua em interlocução com as questões éticas e estéticas implicadas na constituição do comum, agora situando-as no plano da performance coreográfica e da dança contemporânea. Propõe, para este dossiê, um olhar aos processos de Lisa Nelson e de João Fiadeiro, concretizando-os como práticas de atenção, abrindo caminho para pensar o que o jogo também faz. Isabel Penoni e Joana Levi transportam-nos, a seguir, para o campo do teatro contemporâneo, convidando-nos para a viagem-jogo da performance site-specifc "In_Trânsito - Odisseias Urbanas". Enquadrando diferentes tipos de jogo, as autoras trabalham a resultante ambiguidade entre realidade e ficção, nesse atravessamento pelo real contemporâneo. $\mathrm{O}$ artigo seguinte, de Andrea Gaspar, traz-nos o eco da abertura dionisíaca do jogo na pedagogia e experimentação especulativa e dos seus efeitos imprevisíveis no seio do ensino e da aprendizagem da Antropologia a alunos de Licenciatura.

O dossiê aborda, assim, diferentes ativações do jogo, distribuídas entre a antropologia e a performance: inicia com os textos dedicados ao Modo Operativo AND, que atua o jogo a 
partir do deslocamento da antropologia para a performance, e finaliza, inversamente, com uma reflexão situada no deslocamento da performance para a antropologia, propiciadora de experimentações pedagógicas. Entre uma e outra gradação deste trajeto, detêm-se em abordagens e usos performativos do jogo nas artes vivas da dança e do teatro. Por fim, o dossiê fecha-se com um gesto de abertura, acolhendo o foto-ensaio experimental de Débora Baldelli, que explora, a partir de um limiar auto-etnográfico, a relação entre adultos e brinquedos.

\section{BibLIOGRAFIA}

Bateson, Gregory. 1987. Steps to an Ecology of Mind: Collected Essays in Anthropology, Psychiatry, Evolution, and Epistemology. Northvale, New Jersey, London: Jason Aronson Inc.

Benjamin, Walter. 2002. Reflexões sobre a Criança, o Brinquedo e a Educação. São Paulo: Editora 34.

Caillois, Roger. 1990. O Jogo e os Homens: a Máscara e a Vertigem. Lisboa: Ed. Cotovia. Certeau, Michel de. 1998 (1990). A Invenção do Cotidiano. Petrópolis: Editora Vozes.

Csikszentmihalyi, Mihaly. 2002. Fluir: a Psicologia da Experiência Óptima. Medidas para Melhorar a Qualidade de Vida. Lisboa: Relógio d'Água. 1975. Beyond Boredom and Anxiety: Experiencing Flow in Work and Play. San Francisco: Jossey-Bass.

Gadamer, Hans-Georg. 1999. “A Ontologia da Obra de Arte e seu Significado Hermenêutico.” Pp.174-269 em Verdade e Método: Traços Fundamentais de uma Hermenêutica Filosófica, editado por H. Gadamer. Petropólis, Rio de Janeiro: Editora Vozes.

Geertz, Clifford. 1993 (1973). The Interpretation of Cultures: Selected Essays. London: Fontana Press.

Huizinga, Johan. 2003. Homo Ludens: um Estudo sobre o Elemento Lúdico da Cultura. Lisboa: Edições 70.

Millar, Susanna. 1971. The Psychology of Play. London: Pelican Books.

Schechner, Richard. 1993. The Future of Ritual: Writings on Culture and Performance. London, New York: Routledge. Press. 1985. Between Theatre and Anthropology. Philadelphia: University of Pennsylvania

Spariosu, Mihai I.. 1989. Dionysus Reborn: Play and the Aesthetic Dimension in Modern Philosophical and Scientific Discourse. Ithaca, London: Cornell University Press.

Stewart, Susan A.. 1989. Nonsense: Aspects of Intertextuality in Folklore and Literature. Baltimore, London: The Johns Hopkins University Press.

Sutton-Smith, Brian. 2001. The Ambiguity of Play. Cambridge, Massachusetts, London: Harvard University Press.

Turner, Victor Witter. 1992. From Ritual to Theatre: The Human Seriousness of Play. New York: PAJ Publications.

Turner, Victor Witter. 1986. Body, Brain and Culture. Performing Arts Journal, 1 (2): 26-34. Turner, Victor Witter. 1974. O Processo Ritual: Estrutura e Anti-Estrutura. Petrópolis: Editora Vozes. 